\title{
Actual and preferred teacher feedback on student blog writing
}

\author{
Wen-Chun Chen \\ National Chung-Cheng University, Taiwan
}

\begin{abstract}
This research illustrates the provisions and receptivity of teacher feedback in a blogmediated writing project between two colleges. The blog serves as a peer collaboration platform, as well as a mediating tool for teachers to offer timely feedback or prompt student idea exchanges. This paper discusses how teacher feedback may alter in response to students' online writing activities, and examines the reciprocity between the teachers' provision and the students' receptivity. Thirty-four students, two teachers, and two teaching assistants (TAs) participated in the two-semester tele-collaboration. Feedback from the teachers and TAs was categorized by Hattie and Timperley's (2007) taxonomy, which comprises four levels of feedback: the task, the process, self-regulation, and superficial praise. In addition, a new category, mediative feedback, was created to highlight the networked learning. Data were collected from blog message archives, a perception survey, and interviews for qualitative and quantitative analyses. The findings illustrate the evolution of feedback provisions, specifically the addition of mediative feedback type and reduction of superficial comments during online writing tasks. Furthermore, a clear mismatch between the highest rated and most provided feedback type also illustrates the impact of web 2.0 tools on teaching practices.
\end{abstract}

\section{Introduction}

The prevalence of social networking tools, for example, blogs, encourage teachers, especially those in higher education, to break the boundaries of conventional practice logistics and pursue tele-collaborations with distant learner groups (e.g., Chen \& Eslami, 2013; Williams \& Jacobs, 2004). Facing the changes of instructional contexts and media, teacher intervention, specifically feedback, would evolve in response to new learning channels. However, published studies focusing on feedback in digitized higher education are few by comparison with those in other sectors of education (Sadler, 2010); hence, the current research examines this issue with a blog-mediated English (as a foreign language, L2 ) writing project between two colleges in Taiwan.

Although the educational applications of blogs are intended to promote learning, constructive and deep learning does not occur without effective guidance (Arena, 2008; O'Dowd \& Waire, 2009)—successful learning requires much from teachers. Several researchers have cautioned about critical leverage, with one suggesting that novel technology, that is, blogs, doesn't guarantee student interest (Krause, 2005). Also in his book From Blogs to Bombs: The Future of Digital Technologies in Education, Pegrum (2009) emphasized the potential risks of abusing this tool and jeopardizing the intended literacy development if proper instructional guidance is unavailable: "Teachers need the pedagogical competence to work with digital technologies ... they need the skills to deal with the heavy monitoring and mentoring demands" (p. 52) - the professional literacy skills Willis (2001) considered essential in applying novel educational technologies. To further explore this issue, the following research questions are answered in the present study:

(1) What types of feedback do teachers (including TAs) offer on blogs?

(2) How do students perceive teacher feedback of their blog-mediated writing? Is there a match between the feedback most offered and best received?

\section{Literature review}

In an online learning project, due to the reduction (or sometimes the absence) of face-to-face communication and social pressure, teacher mediation and feedback are critical to student collaboration (Williams, Brown, \& Benson, 2013). In this section, teacher feedback is grounded in web 2.0-mediated L2 learning contexts, building on research and frameworks derived from conventional classroom practices. Feedback is conceptualized as “information provided by an agent regarding aspects of one's 
performance or understanding" (Hattie \& Timperley, 2007, p. 81). Simpson (2013) delineated its importance in modern higher education as formative assessment to enhance online learning: "Feedback drives learning" (p. 55). Paradoxically, Sadler (2010) argued that "the mere provision of feedback does not lead to improvement" (p. 536). Consequently, the complexity of feedback practice is obvious.

\section{Feedback foci in conventional and modern teaching practices}

To ensure various findings are presented systematically, scholars have engaged in meta-analyses to draw findings of related studies into a common measure (effect sizes) "so that overall impacts on learning could be determined" (Lloyd \& Trangmar, 2012, p. 60). Kluger and DeNisi (1996) offered a preliminary synthesis discussing teacher feedback, and speculated that some feedback types are more powerful than others, judging by the variance of effects of feedback on student performance. They concluded that feedback itself does not necessarily have positive effects, and learning outcomes do not always correspond to provision quantity. Expanding on this work and accentuating the pedagogical practicality, Hattie (1999) conducted a massive meta-review of classroom practices and concluded with three critical questions all teachers should contemplate: "Where am I going? (What are the goals?), How am I going? (What progress is being made toward the goal?), Where to next? (What activities need to be undertaken to make better progress?)"(p. 88). In response, Hattie and Timperley (2007) further proposed an updated conceptual analysis and a model to guide teachers to reflect and to offer effective feedback. The researchers inductively proposed four operational types (levels) of feedback for teachers to scaffold students toward desirable outcomes or goals, while urging practitioners to consider contextual factors, for example, task design (specifications), provision timing, and learning ambience/contexts. The four levels concern task, task processing, self-regulation, and the self (as a person). Feedback about task mainly focuses on task product; this feedback type "may include directions to acquire more, different, or correct information [in order to improve the product quality]" (p. 90). Task processing targets the process used to create or complete a task/product, that is, "the processing of information or learning process" (p. 90)more about strategy instruction. Self-regulation entails self-evaluation or self-efficacy to engage or push further toward task excellence. Feedback about self as a person is unrelated to learning, but is directed to the person (student). The first three represent three cognitive foci in a hierarchical order, starting from local to global errors, from surface to deep learning, from easy to difficult strategies, from immediate to long-term performance, and from tangible (concrete) to abstract advancement. By contrast, feedback about the self as a person was included for its frequent presence, not for its pedagogical effect. Examples of the four-level framework are provided in the Method section, as it is the analytical structure of the current research.

The four feedback foci steer teachers to "decide what to say" (Brookhart, 2008, p. 19) in the attempt to move students forward toward expected outcomes, that is, "feedforward" (Sadler, 2010, p. 538). Boud and Molloy (2012) explored how the framework can orient students toward a pre-determined curriculum in higher education. Through feedback-design episodes (design implies planned not spontaneous feedback content), they exemplified how and when teachers distinguished between micro- and macrodecisions, that is, low vs. high (local vs. global) level comments, in response to learning behaviors. Proper decisions should subsequently lead to "feedback interactions" (p. 203) and curricular objectives. As higher education moves toward the digital learning era, new forms of learning challenge the classic framework: instruction is often mediated via new technologies, and teacher-student communication is frequently written without much in-person contact. Bokhove (2010) applied the same framework to online statistics learning in an attempt to build a digital feedback provision system prototype. Unfortunately, due to limited error predictability, this feedback taxonomy was supportive but not exhaustive - the coverage was inadequate. The necessity of teacher presence and feedback customization appeared to affect Bokhove's (2010) results:

Students' positive experiences during the interaction online could be promoted by the instructors' providing prompt feedback, participating in the interaction, encouraging social interaction, and employing collaborative learning strategies (Tallent-Runnels et al., 2006, p. 101).

Error prediction and correction in other subjects, such as writing, is far less straightforward than mathematics (Parr \& Timperley, 2010). Parr and Timperley also employed the framework in a writing project and found that the power of feedback relied heavily on teachers' abilities to (a) give quality 
comments, namely fully delivering their content knowledge through effective written communication; and (b) make reliable judgments of learners' work (accurate error diagnosis) through the process of focus referencing. Accordingly, it is clear that "feedback is more productive to consider when and how it is received rather than when or how it is given" (Hattie \& Gan, 2011, p. 250). Teachers' challenges are greater with L2 learners in a networked learning milieu, where students' interpretations and receptivity of feedback might differ from their native speaking counterparts - "[it] depends not only on the kind of feedback provided, but also on how the learner deals with feedback information" (Krause, Stark, \& Mandl, 2009, p. 160). The abovementioned helps teachers understand the impact of new instructional media and contextual factors which challenge the robustness of Hattie and Timperley's (1997) framework. Overall, it is fair to say that the significance of teacher feedback is greater in online learning tasks than in physical classrooms.

\section{Teacher feedback in L2 writing}

In conventional classroom practices, Fathman and Whalley (1990) proposed that L2 learners benefit most when content- and form-focus (global and local) issues are equally addressed. Be that as it may, Cohen and Cavalcanti (1994) revealed the discrepancy between teachers' concerns and students' interests in feedback foci: comments often are not interpreted or expressed as intended. Students strongly sensed that error corrections on form rather than content were the predominant focus in essay writing - despite the teachers' different perceptions. Frequently, teacher feedback preference is influenced by the design of proficiency tests. Lee (2008) also pointed out that feedback is often teacher-centered which leads to students' passive and dependent learning attitudes. One consistent finding also appeared in the above studies: students exert much time making sense of teachers' handwriting on paper-based assignments, which could imply haste on the teacher's part. Overly brief comments (in the margin or line spaces) may also cause confusion. These problems indicate the complications of teacher feedback. When technology is reshaping higher education, what other issues will emerge when mediums change, and when instruction is typed and elaborated in the form of online posts?

From L2 learning perspectives, networking technologies can boost learning motivation (Pinkman, 2005), autonomy (Mynard, 2008), positive attitudes (Bakar \& Ismail, 2009), linguistic awareness (O'Dowd \& Waire, 2009), content organization (Arslan \& Şahin-Kızıl, 2010), intellectual exchanges (Chen, 2012b), linguistic ownership (Chen, 2012a; Chen \& Eslami, 2013), and self-expressions and a sense of community (Levy, 2009). Nonetheless, few empirical studies have addressed the effect of teacher intervention in L2 online tasks; specifically feedback content remains underexplored. In an online context where in-person contact and social cues are reduced, interlocutors often feel compelled to close the gap between each other and hence tend to explicate or negotiate more (Chen \& Eslami, 2013). Yet message receivers' interpretations and reactions can still be unpredictable. Wu (2006) investigated L2 blogs and revealed that learners' receptiveness and attitudes can cause positive or negative changes in response to the same feedback. Additionally, in Liu and Shih (2007), prompt and directive cues were remedial when their participants (despite the high L2 proficiency) failed to autonomously perform the peer review tasks on blogs; however, after teacher intervention, discussion quality improved significantly. Procedural facilitation to help students understand teachers' expectations was highlighted for the success of online L2 projects. Sun (2009) also underlined the necessity of timely, individual feedback, especially during speedy online exchanges when meaning and form in L2 can be doubly challenging for the learners with various proficiency levels. Gass (1997) delineated this catalyst effect in which teacher feedback induces an "externally created salience" (p. 114) - to raise learner's awareness. She also conceptualized explicitness and directness as two axes differentiating feedback types. Reflecting on Hattie and Timperley's (2007) feedback hierarchy, task focus is on the explicit and direct end while regulative focus inclines toward the implicit and indirect end, with processing type in the middle. Based on Chen and Eslami (2013), learning outcomes are more likely to occur when directness and emphasis increase in online feedback, for example, comments on language forms often fits the profile. However, many attention-drawing tactics would be required to compensate the reduced physical presence and the message display. This complication of feedback provision deserves more attention in modern, digital higher education where "tasks are divergent rather than convergent, and complex rather than simple" (Sadler, 2010, p. 535).

In an environment requiring students to demonstrate cognitive skills or professional proficiency, Sadler (2010) connected feedback provisions and receptivity: "teachers who are committed to providing high- 
quality feedback want it to work for their students. Complementary attention should therefore be directed to what students make of the feedback" (p. 539). This assertion highlights the value of the current study. First, it addresses the rich interactivity of tele-collaboration: multi-directional interactions between peers, with teachers and TAs, from inside and outside of school, between casual and formal writing discourse. Second, teachers' cross-institutional facilitation is examined openly and objectively. Third, teacher feedback operation in relation to L2 learners' receptivity is concurrently scrutinized in a cross-referenced manner to re-assess a classic framework. This new learning platform calls for more empirical research to address the evolution of feedback provision and receptivity in L2 learning projects.

\section{Method}

\section{Participants and project setup}

Thirty-four college-level Language and Literature majors from two colleges in Taiwan engaged in blogmediated discussions in English with e-pals for two semesters. They reflected on weekly topics under the theme self-awareness. Participants were enrolled in two English courses targeting conversational skills and academic English development. The two female instructors (one as the author of this paper), supervising their two TAs, mediated the project's execution between the two institutions. The instructors were both full-time college professors specializing in Language Education, with years of language teaching and educational technology experience and $\mathrm{PhD}$ degrees from the United States. The two TAs were graduate students in Teaching English as a Foreign Language (TEFL) master's degree programs, and assisted this project by offering comments on students' essay writing. All participants signed a consent form for their data to be used in this paper.

Topics for weekly discussions emerged naturally via social news or current events. Concept/value identification was designed to elicit a wider range of lexical knowledge from learners (Skehan, 1998), for example, Task 6: Anger management, inspired by a controversial verdict in the Asian Taekwondo Games. Students were expected to reflect on the prompts and share responses with e-pals. Figure 1 shows the implementation flowchart. In the first week, students met each other via videoconferencing to establish a sense of social presence. Each cross-institutional group constructed a blog linked to the project website and accessible to all students, teachers, and TAs. The cyber-collaboration was also structured as a safe environment, allowing L2 learners to verify their linguistic hypotheses (Chen \& Eslami, 2013). The instructors and TAs monitored students' interactions and offered feedback to facilitate tasks.

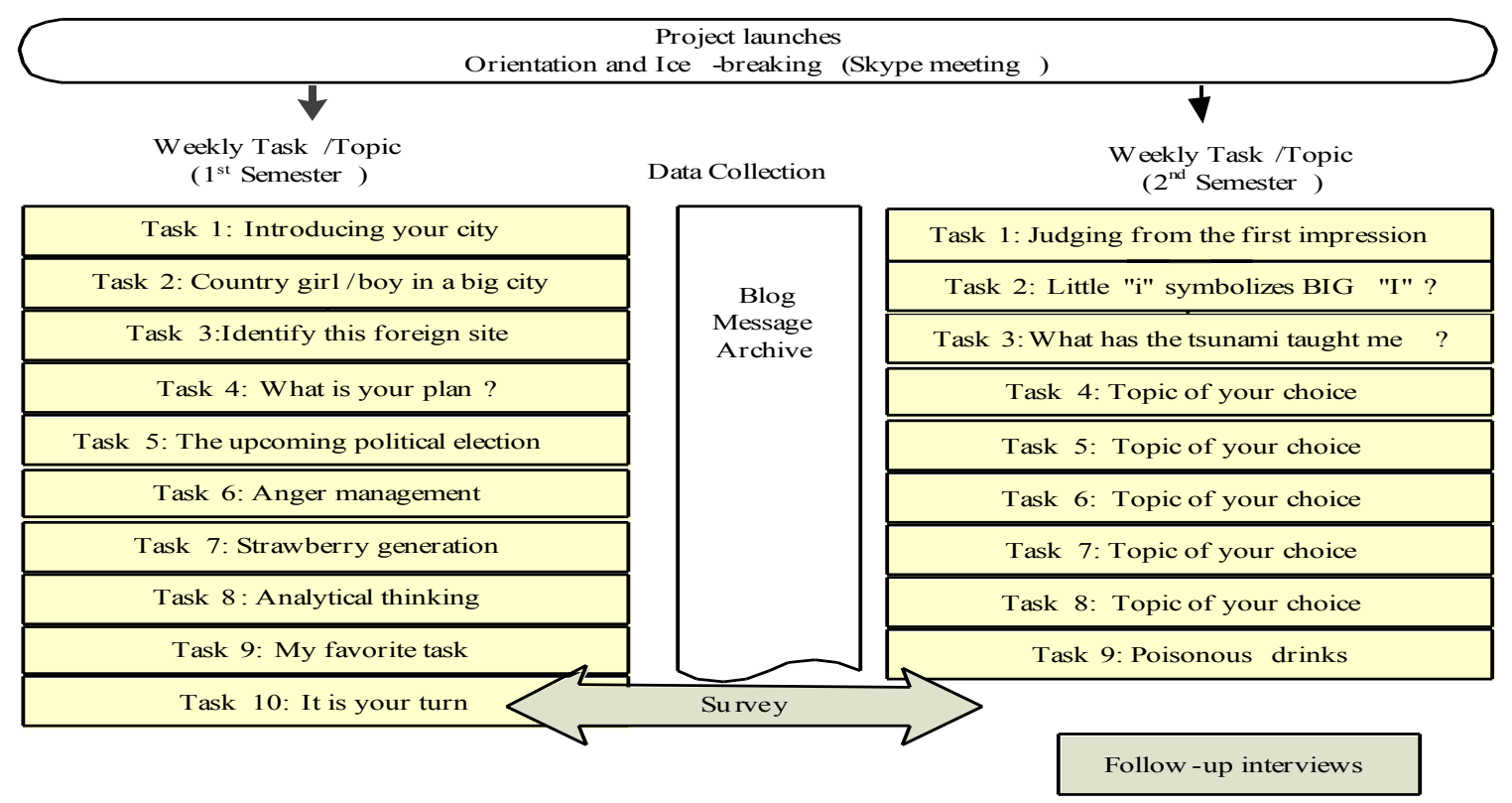

Figure 1. Implementation flowchart and the weekly tasks/topics. 


\section{Data collection and analysis}

Both qualitative and quantitative data were collected to holistically examine teacher feedback on blog posts, the results of two end-of-semester surveys, and follow-up interviews with students, instructors (A, B) and TAs (C, D). The coding of the feedback, the quantity of feedback in each category, and students' perceptions of five feedback types are the three main points in this section. Findings are then triangulated with the interview data. Please note that data analysis approaches were not considered until the end of the project; hence, the instructors and TAs, as well the feedback they offered, were not influenced by the following analytical framework during the blog project.

The coding of teachers' feedback comments on blogs

After the project was completed, Hattie and Timperley's (2007) taxonomy was chosen as a suitable analytical framework to characterize teacher feedback on blog posts. The frequency counts offer a macroand micro-view on the types of feedback teachers offered. The clearly defined taxonomy operationally resolved the inconsistency among multiple providers. All the example excerpts presented here are from the actual data and in their original, unedited form.

(1) Feedback about the task: This type of feedback includes information about the depth or quality of the final task product - also called corrective feedback because it underlines errors and aims to correct them. Brookhart (2008) noted its limitation: it may not transfer to other tasks because it is specific to the particular error/direction of the very assignment. An example from the actual data of the current study is: "I am not following your logic here, what you meant by "trade-off", will you clarify it?"

(2) Feedback about the processing of the task: This feedback level gives students information about how they approach the task and alternative strategies during the task engagement. It is more cognitively demanding and is therefore more difficult than the first type. An example is: "When discussing these types of controversial issues, we want to be more careful about our word choice. For instance what you said about ... might offend some people ... perhaps you can use a milder/neutral tone of voice".

(3) Feedback about self-regulation: This type facilitates students' self-monitored control and confidence in their learning, and consequently, involves affective factors; hence, the objective is more challenging and broader than the previous two. An example is: "Where did you find all the great statistical evidence? Would you like to share/revisit the information source and see if they could help you build a stronger claim?"

(4) Feedback about the self as a person: Comments like "Smart girl!" refer to issues beyond the task or students' learning performance and thus require caution. Superficial praise can be as distracting as negative comments because they are both uninformative and possibly counterproductive. To accentuate this attribute for readers, this type is relabelled as superficial praise hereafter.

It was found, however, that during the analysis process, most of the TAs' feedback and some of the teachers' comments - in an attempt to boost interaction-did not fit into the four abovementioned categories. For this reason, a fifth category termed mediative feedback was created, which serves to (a) fill the gap/silence and stimulate more interaction between students when failure to promptly reply occurred; and (b) allow teachers and TAs to connect with students as well as share their personal opinions. An example is: "I would like to see some personal reflection on this issue. Julie, would you like to share your overseas experience with us?" In a nutshell, this feedback type occurred when teachers (or TAs) joined in to discuss the topics rather than commenting on the students' writing. More categorized excerpts are available in the Appendix.

Teacher and TA feedback was collected from the blogs and classified into the above five types for frequency counts. Initially four raters all coded the same quarter of the data to establish inter-rater reliability and then met six times to compare results. After reviewing the differences, detailed clarifications allowed the raters to re-establish agreements. Then, they worked individually to process the remaining three quarters of the data, yet still met when confusions occurred to re-calibrate the coding scheme. 


\section{End-of-the-semester surveys}

This perception survey helped reveal students' preference for the types of feedback. The researcher adopted the stimulated recall technique that Gass and Mackey (2000) introduced, selecting feedback excerpts collected from the two semesters. Excerpts served as recall tools in the two rounds of online surveys for the students to report their reactions to teachers' feedback (surveys can be obtained from the author upon request). Among the 20 items (10 from each semester), 17 were from the actual data, with the remaining three fabricated for the category of superficial feedback (due to the insufficient amount of examples) to elicit students' full reactions. Multiple-response items were offered, and students checked whichever option best described their feelings, which constitutes a modification made based on a pilot study (cf., Chen and Shih, 2010). The other participating instructor reviewed the chosen excerpts and agreed that the constructs were representative of the five categories. Take the following item as example: "What you said about females' independence sounds great. Can you elaborate on it more?" Students had a choice of 17 descriptors, in addition to others, to indicate their feelings toward teachers' feedback. These descriptors were categorized into positives and negatives:

- Positives category: clear, I'm reminded, useful for future self-correction, attention from the teacher, motivating, constructive, alert, inspired, appreciated

- Negatives category: vague, hard to understand, confusing, too personal, not to the point, ashamed, embarrassed, irrelevant

- $\quad$ Other(s)

The above descriptors were collected from three of the participants who reviewed the excerpts and helped brainstorm possible reactions before the survey was finalized.

\section{Follow-up interviews}

Eight of the participants from both schools volunteered for follow-up interviews conducted three weeks after the project. In all interviews, the TA posed two predetermined questions aligned with the researched constructs: (1) How did you feel about the teachers'/TAs' feedback? and (2) Was the teacher's feedback the same or different from conventional writing activities? During the interviews, the researcher observed and intervened occasionally to seek clarifications. This part of the data collection served as a member check (Lincoln \& Guba, 1995) to verify the interpretations of the findings from the blog archives and the survey. Afterwards, the teachers and TAs formed a focus group to exchange their reflections on their execution of feedback provisions and students' performance and responses via net-conferencing. The process was video recorded and then reviewed.

\section{Results and discussion}

In this section, findings are sequentially reported and discussed in an integrated manner according to the two research inquiries. The focus is to scrutinize the content of teacher feedback (coding results), and the fit between actual provision (from the comments on blog posts) and students' receptivity (from the perception survey results). Interview results help interpret the numerical data.

\section{Feedback types and occurrences}

To answer the first research question, teacher feedback was classified and reported by frequencies and percentages under the five categories (Table 1) over the two semesters. A total of 494 instances of teacher feedback were identified: 254 during Semester 1, and 243 in Semester 2. The overall categorical results are shown in Table 1, in which subtotals of the two respective semesters were calculated in percentages. Except for mediation and superficial praise, the rank of the other three feedback foci correspond to the ordinal levels in Hattie and Timperley's (2007) taxonomy-the lower levels had more occurrences. This result is similar to conventional writing practices in that teachers' instinctive and habitual tendency is to focus more on immediately fixing local problems, as compared to facilitating transferrable skills or cultivating students' self-efficacy. 
Table 1

Results of teacher categorical feedback instances

\begin{tabular}{lcccc}
\hline Feedback Type & Semester & Subtotal & Total & $\%$ \\
\hline Task feedback & Sem 1 & $95(37.8 \%)$ & 165 & $33.4 \%$ \\
Process feedback & Sem 2 & $70(28.8 \%)$ & & \\
& Sem 1 & $43(17.1 \%)$ & 81 & $16.4 \%$ \\
Self-regulation & Sem 2 & $38(15.6 \%)$ & & \\
feedback & Sem 1 & $10(4.0 \%)$ & 13 & $2.6 \%$ \\
Superficial feedback & Sem 2 1 & $3(1.2 \%)$ & & \\
& Sem 2 & $1(0.4 \%)$ & & $0.2 \%$ \\
Mediative feedback & Sem 1 & $102(40.6 \%)$ & & \\
& Sem 2 & $132(54.3 \%)$ & & $47.4 \%$ \\
Grand total & Sem 1 & $254(100.0 \%)$ & & \\
& Sem 2 & $243(100.0 \%)$ & 494 & $100.0 \%$
\end{tabular}

Note. Percentages enclosed in parentheses are calculated by the subtotals of two separate semesters, to indicate the constituents of the feedback entity of the two respective semesters.

Furthermore, the fact that both the teachers and TAs focused heavily on mediation was intriguing: they purposefully focused on promoting between-group synergy and extending conversations among group members. More specifically, they looked beyond grammatical or organizational problems commonly addressed in traditional classroom writing activities. Compared to other categories, which showed minor differences in percentages between the two semesters (all less than 9\%), this newly emergent feedback type had a more obvious increase, from $40.6 \%$ to $54.3 \%$. The feedback providers all reflected in the interview that they noticed fewer prompt posts toward the end of the second semester and hence deliberately pushed the students to resume dialogues. Chen (2012a) and Chen and Eslami (2013) also reported a similar situation - the landing-and-taxing effect-at the final stage of their tele-collaboration projects. This finding illustrates that the teacher's role evolved from simple "omniscient informant" (Kern, Ware, \& Warschauer, 2004, p. 249) to facilitator, mediator, and/or dialogue-builder under the special affordance influence of social media for new forms of cooperative learning (Levy, 2009).

In contrast to the high frequency mediative type, superficial praise rarely occurred-the opposite to what Hattie and Timperley (2007) contended as "too often used" yet "unlikely to be effective" (p. 96) in many class situations. Instructor A in this project confessed in the interview that "It was impossible for me to make personal comments since I did not know them [the students in the distant group]." Instructor B then explicated her conflict-avoiding attitude toward the partners (also mentioned in Müller-Hartmann, 2007) stating that "I wanted to show that I treated every participant equally. If I only praised my student like 'You're brilliant!', their partner might feel ignored. So I rather not." The indirectness of online interaction, although often being challenged (e.g., Pegrum, 2009), surprisingly reduced the occurrence of superficial praise in this project. Teachers focused more on the tasks, the process, self-regulation, and mediation aspects of collaborative learning.

Self-regulation feedback, as the other low frequency type, unfortunately appeared only 13 times during the entire project. The four feedback providers were asked to recall why this highly recommended type was rare compared to the others. The two TAs read the 13 excerpts the two teachers provided and frankly stated that this type was unfamiliar to them. "I honestly did not think about offering this type of feedback. It is beyond my knowledge and my ability. Plus, I didn't receive many of those in my undergrad ... I just simply didn't know how to do it," said TA C with a helpless look during the interview. TA D responded: 
Look very time-consuming. I was too busy monitoring the regularity of their submissions, and wanted to promptly offer quick assistance on their grammar mistakes or word choices, which were too many already you know... Luckily, the instructor asked me to focus on major errors, or I would spend too much time.

Evidently, achieving the goal of cultivating students' higher order thinking, internal feedback, and selfassessment were beyond their current skills as novice teachers. Further, the two teachers also conceded that to offer this type of comment, many requisites existed: proper delivery, recipient familiarity, workload management, elaborative scaffolding, and multiple rounds. Below are related excerpts:

Instructor A: "Knowing the students well enough so you know how to challenge him in the way s/he can accepts."

Instructor A: "Reviewing individual students' or the dyadic e-pals' past performance for weeks or even months before you know how to build their self-efficacy... this is time-consuming and unmanageable, especially with the students in the distant group."

Instructor B: "Starting with tangible errors and giving concrete examples [at task and process levels] as the background, from which you move on to the tougher challenges ... online feedback is different from paper-based. You can't add in-text comments but only big blocks at the end which often takes a lot of writing."

Instructor B: "Ending this type of feedback with a question mark — to get the students think. At times they would seek clarifications or confirmation ... I would need to develop from students' response to my first-round feedback and 'raise the bar' at the second round, which doesn't often happen within the timeframe. Not to mention that most of them are still shy. Nonetheless, when it did happen, I felt rewarding."

Providing self-regulation feedback presents students with opportunities to learn to ask, "How important is this error or mistake?" (Ware \& Canado, 2007, p. 118), and also signals teacher expectations and understandings of individual students' achievable levels (Nicol \& Macfarlane-Dick, 2006). Hence, this type of feedback can often be misinterpreted as doubtful or critical (Aljaafreh \& Lantolf, 1994), especially when personal rapport is absent or the message is not cautiously phrased. These reasons explain the reluctance and restraint in offering this type of feedback. Despite the possible rewarding outcomes, fear of an unmanageable workload after incorporating blog projects in L2 classrooms, monitoring multiple daily-updated messages, and offering individual feedback, can be intimidating.

\section{Provision and receptivity}

To explore how (well) students received teachers' feedback (the second research inquiry), at the end of each semester students filled out an online feedback evaluation survey (see Appendix). Table 2 summarizes the analysis results of the 20 feedback excerpts, with four items from each category. Later in the interviews, some participants explained that the extremely low numbers of negative hits indicate the students' overall appreciation of feedback in all aspects: "Teachers and TAs projected themselves as interested readers with their feedback, and this time we had several [including e-pals] who would be waiting to read what we had to say-this made me want to write more", one interviewee expressed eloquently. 
Table 2

Students' evaluation on the 20 feedback excerpts

\begin{tabular}{|c|c|c|c|c|c|c|c|c|}
\hline \multirow[t]{2}{*}{ Feedback type } & \multicolumn{4}{|c|}{ Positive hits } & \multicolumn{4}{|c|}{ Negative hits } \\
\hline & Semester & Subtotal & Total & $\%$ & Semester & Subtotal & Total & $\%$ \\
\hline \multirow[t]{2}{*}{ Task feedback } & Sem 1 & 43 & \multirow[b]{2}{*}{88} & \multirow[b]{2}{*}{$19.09 \%$} & Sem 1 & 4 & \multirow[b]{2}{*}{7} & \multirow[b]{2}{*}{$23.33 \%$} \\
\hline & Sem 2 & 45 & & & Sem 2 & 3 & & \\
\hline \multirow[t]{2}{*}{ Process feedback } & Sem 1 & 58 & \multirow[b]{2}{*}{101} & \multirow[b]{2}{*}{$21.91 \%$} & Sem 1 & 5 & \multirow[b]{2}{*}{8} & \multirow[b]{2}{*}{$27.67 \%$} \\
\hline & Sem 2 & 43 & & & Sem 2 & 3 & & \\
\hline \multirow{2}{*}{$\begin{array}{l}\text { Self-regulation } \\
\text { feedback }\end{array}$} & Sem 1 & 65 & \multirow[b]{2}{*}{138} & \multirow[b]{2}{*}{$29.93 \%$} & Sem 1 & 1 & \multirow[b]{2}{*}{1} & \multirow[b]{2}{*}{$3.33 \%$} \\
\hline & Sem 2 & 73 & & & Sem 2 & 0 & & \\
\hline \multirow[t]{2}{*}{ Superficial praise } & Sem 1 & 40 & \multirow[b]{2}{*}{75} & \multirow[b]{2}{*}{$16.27 \%$} & Sem 1 & 2 & \multirow[b]{2}{*}{5} & \multirow[b]{2}{*}{$16.67 \%$} \\
\hline & Sem 2 & 35 & & & Sem 2 & 3 & & \\
\hline \multirow{2}{*}{$\begin{array}{l}\text { Mediative } \\
\text { feedback }\end{array}$} & Sem 1 & 29 & \multirow[b]{2}{*}{59} & \multirow[b]{2}{*}{$12.81 \%$} & Sem 1 & 4 & \multirow[b]{2}{*}{9} & \multirow[b]{2}{*}{$30.00 \%$} \\
\hline & Sem 2 & 30 & & & Sem 2 & 5 & & \\
\hline \multirow[t]{2}{*}{ Total } & Sem 1 & 235 & \multirow[b]{2}{*}{461} & \multirow[b]{2}{*}{$100 \%$} & Sem 1 & 16 & \multirow[b]{2}{*}{30} & \multirow[b]{2}{*}{$100 \%$} \\
\hline & Sem 2 & 226 & & & Sem 2 & 14 & & \\
\hline
\end{tabular}

At first glance, most feedback items were well received (461 positive hits and 30 negative); in the interview students also confirmed that they always welcomed feedback (the expression "the more the better" appeared in the interview). Unfortunately, a discrepancy is clear between the most offered (see Table 1) and the best rated feedback types (see Table 2). Feedback targeting self-regulation, despite the fact that it was seldom offered (3\%), was valued the most by the students (138 positive hits, constituting $28 \%$ of all hits, and only one negative). By contrast, mediative feedback received the fewest positive hits (59 positive hits, constituting $13 \%$ of all hits, and nine negative), yet was the most commonly offered type (a total of $47 \%$ ).

The mismatch between the least offered and the best received feedback indicates that students preferred to see more in-depth guidance that is "worth the effort" (Brookhart, 2008, p. 21), despite the extra learning efforts, self-evaluation, and analytical interpretations (Hattie \& Timperley, 2007). It is also note-worthy that the online medium and informal discourse also softened the challenge from the teachers. In spite of the high expectation and cognitive complication this type of feedback targeted, several students expressed in the follow-up interviews that the undertone of blogging discourse [of less formal style] seemed to reduce the power (authority) distance (Hofstede, 1986) between teachers and students. Without feelings of intimidation, they welcomed feedback that triggered higher order thinking. They began to take the audience into consideration, felt appreciated, and stopped worrying about grammatical corrections (all student names below are pseudonyms):

When blogging, I took it as I was having a chat with my partner. Whatever I said should make sense [to him]. But my teacher showed me my blind spots and asked me for clarifications. Now I began to have my audience in mind, like if they have enough background information or not, when posting my opinions. (Terry)

Teachers seemed to be chatting with me and genuinely felt interested in my thoughts, not really criticizing my writing like most of the English assignments. Their tone of voice is quite informal, like "gonna" or "ya know" this kinda very casual online language. They never say this in the classroom or on my papers. (Judy) 
Online communication is known for its low formality and high tolerance of discourse variety or minor errors, especially when moving into web 2.0 and the global era (Chen \& Eslami, 2013). Users' openness transcends cultural differences and English speakers' status (native vs. non-native) as well as educational conventions (e.g., English writing in this case). Teacher-student power distance under the influence of Asian culture was buffered or partially reduced as a result of indirect contact and discoursal features. If openness is better promoted in classroom-based online projects, learners' affective filters or reservedness can be reduced due to their confidence in commanding L2, which otherwise would have impeded them from pursuing clarifications with regard to teachers' initial feedback (Jones, 1999), and eventually lead to an increase in the occurrences of this feedback type.

The least preferred type (see Table 2) was mediative feedback. According to the students' verbal reflection in the interviews, several acknowledged the good intentions behind mediative moves but underestimated the instructional value: "Professors want me to use English every day for real discussion and write more, TAs tend to give encouragements and reminders of submissions ... but in a long run, I still want to see how I can improve myself", said Pauline, a sophomore participant. Another student Danny, however, embraced mediative feedback as experiential input: "to make us open up to tackle on sensitive topics, they showed us different angles of the issues by sharing their own stories ... but I need explicit guidance to learn more." Students felt encouragement and supervision through mediative feedback, but did not receive it as an agent of direct, substantial instruction. Nevertheless, mediation is essential in distance learning environments for it increases participants' sense of social presence, which fosters a sense of community among learners and interactivity with teachers and peers (Joyce \& Brown, 2009; William et al., 2013). Although this strategy should not be overused, it is essential for the telecollaborative milieu where in-person contact and instant cues are absent.

Superficial praise also received a low number of positive hits. Several students doubted the meaning behind this type of comment: "it was like they didn't know what else to say ... or just like a quick acknowledgement of reading my posting" (Keven). Luckily, the presence of superficial praise was rare throughout the project. It seems fair to conclude that online projects help teachers focus more on learning tasks and processes, and also reduce the effects of pre-existing personal impressions of the students (Cohen \& Calvalanti, 1994). The mid-ranked types were about task processing and tasks, and were easily offered and received. In the interviews, students collectively expressed that these two types are very similar to what they usually receive from conventional composition assignments and acknowledged that the specificity helps them engage in self-corrections and strategy use. Most importantly, they were presented with a chance to retrospectively examine their own writing habits when the teachers/TAs raised concerns within a dyad, using the e-pals' work as tangible examples to illustrate the targeted language problems or logic issues in a textual and relaxed context.

\section{Conclusion}

Findings of the present study illustrate how blog-mediated collaboration between distant partners can affect teacher feedback foci, the taxonomy and occurrence. The classic framework (proposed by Hattie and Timperley, 2007) no longer accommodates learning projects involving network technologies, multiple partner groups and feedback providers. Specifically, the major reduction of superficial praise and new addition of mediative moves deserve special attention. When placing feedback provision and receptivity on the same baseline, an apparent mismatch emerged. First, feedback about self-regulation was perceived as most beneficial, yet was also the least offered among the five feedback types (namely task, process, self-regulation, superficial praise, and mediation). The teachers and TAs revealed how and why provision of the self-regulation type was difficult for them as much as for the students. In online projects, similar to conventional classroom practices, the build-up behind this highest cognitive level of feedback required much writing, teaching experience, skilful expression, and personal rapport. For the students, although this feedback type implied more effort, online discourse could soften teachers' expectations; hence, the challenges were well-received. Second, the most offered yet lowest rated mediative feedback, despite its function to prompt interactions and personal connections, was underestimated as neither instructional nor informative. Third, superficial praise, which is frequent in classrooms, was almost absent in this online project as a consequence of multiple feedback sources and distant recipients - the features of tele-collaboration. Task and process-focused types were familiar to the students due to students' frequent encounters in conventional writing classes - they ranked middle. The modified taxonomy grounded in tele-collaborative L2 learning projects revealed the effects of medium; 
feedback content and foci should align and evolve with the feedback delivery channel, the setup of the collaboration, and instructional objectives to accommodate e-generation students' expectations and preferences. Teachers, as much as learners, should recognize the strengths and weaknesses of each feedback type, and calibrate between provision and receptivity. The analytical framework used for the current study can serve as training material for teachers to offer appropriate feedback to meet their instructional objectives when implementing similar projects in the future.

It should be noted that no attempt was made to make this blog-writing project a stand-alone writing curriculum, but rather as a partially blended context (half online, half face-to-face): teachers and students still know half of the participants (home group) and occasionally discussed their performance in class. To develop professional literacy skills in a blended classroom, teachers and TAs should build a seamless connection between face-to-face and online instruction, engaging in self-efficacy or -regulative reinforcement in class since online feedback of self-regulation requires much effort. Similarly, TAs could also verbally mediate in person rather than excessively posting reminders or encouragements online. It should also be noted that this project aimed at topic discussions between college students from different socio-ecological surroundings. Therefore, English was intended to be devised as a conversation tool where linguistic accuracy (language form) was not prioritized unless the errors impeded comprehension. In other words, English (as an international language) communicability and ownership were the goals. The biggest limitations of the study were the duration of each discussion topic and the small participant sample size. One week of asynchronous blog-mediated discussions did not allow for multiple turns of dyadic and teacher-student dialogues. It is suspected that if each discussion cycle could have lasted longer (approximately two weeks), more substantial remarks and higher level feedback would foster learners to further elaborate their ideas and generate more complex discussions. Future research is encouraged to examine the transferability of the modified feedback taxonomy in similar networked L2 learning projects. The communication mode between asynchronous and synchronous or between textual and audio could create a major impact on teachers' instructional decisions and strategy use.

\section{Acknowledgements}

I am grateful of the 34 participants and two TAs in the study. Special gratitude is extended to Dr Doris Shih and her students from Fu-Jen University for assisting in this project. This research was partially funded by National Science Council (NSC 102-2410-H-194-038) and Minister of Science and Technology (MOST 103-2410-H-194-033) in Taiwan.

\section{References}

Aljaafreh, A. L. I., \& Lantolf, J. P. (1994). Negative feedback as regulation and second language learning in the zone of proximal development. The Modern Language Journal, 78, 465-483. doi:10.1111/j.1540-4781.1994.tb02064.x

Arena, C. (2008). Blogging in the language classroom: It doesn't simply happen. TESL-EJ, 11(4), 1-7. Retrieved from http://www.tesl-ej.org/wordpress/

Arslan, R., \& Şahin-Kızıl, A. (2010). How can the use of blog software facilitate the writing process of English language learners? Computer Assisted Language Learning, 23, 183-197. doi: 10.1080/09588221.2010.486575

Bakar, N. A., \& Ismail, K. (2009). Using blogs to encourage ESL students to write constructively in English. AJTLHE, 1(5), 45-57. Retrieved from http://pkukmweb.ukm.my/jtlhe/Archives.aspx

Bokhove, C. (2010). Implementing feedback in a digital tool for symbol sense. International Journal for Technology in Mathematics Education, 17, 121-126. http://www.tech.plym.ac.uk/research/mathematics_education/field\%20of\%20work/IJTME/

Boud, D., \& Molloy, E. (2013). Decision-making for feedback. In D. Boud \& E. Molloy (Eds.), Feedback in higher and professional education: Understanding it and doing it well (pp. 202-218). New York, NY: Taylor \& Francis.

Brookhart, S. M. (2008). How to give effective feedback to your students. Danvers, MA: Association for Supervision and Curriculum Development.

Chen, W. C. (2012a). Professional growth during cyber collaboration between pre-service and in-service teachers. Teaching and Teacher Education, 28, 218-228. doi:10.1016/j.tate.2011.09.010 
Chen, W. C. (2012b). A trilateral telecollaborative model for cross-border/-cultural task negotiation: The pilot study for virtual academic discussions in ELF. In C. L. Wei (Ed.), Globalization and digitalization: Pedagogical challenges and responses (Vol. 3, pp. 63-80). Taipei: Crane.

Chen, W. C. \& Eslami, Z. (2013). Focus on form in live chats. Educational Technology \& Society, 16, 147-158. Retrieved from http://www.ifets.info/

Chen, W. C. \& Shih, Y.-S. D. (2010). Cultivating linguistic ownership through reflective blog-writing: A college-level dyadic collaboration through Web 2.0. In Z. e. a. Abas (Ed.), Proceedings of Global Learn Asia Pacific 2010 (pp. 291-297). Penang: AACE.

Cohen, A. D., \& Cavalcanti, M. C. (1994). Feedback and compositions: Teacher and student verbal reports. In B. Kroll (Ed.), Second language writing (pp. 155-177). New York, NY: Cambridge University Press.

Fathman, A. K., \& Whalley, E. (1990). Teacher response to student writing. In M. H. Long \& J. C. Richard (Eds.), Second language writing: Research insights for the classroom (pp. 155-177). New York, NY: Cambridge University Press.

Gass, S. M. (1997). Input, interaction, and the second language learner. Mahwah, NJ: Erlbaum.

Gass, S. M., \& Mackey, A. (2000). Stimulated recall in second language research. Mahwah, NJ: Erlbaum.

Hattie, J. (1999, June). Influence on student learning (Inaugural lecture, University of Auckland, New Zealand). Retrieved from https://cdn.auckland.ac.nz/assets/education/hattie/docs/influences-onstudent-learning.pdf

Hattie, J., \& Gan, M. (2011). Instruction based on feedback. In R. Mayer \& P. Alexander (Eds.), Handbook of research on learning and instruction (pp. 249-271). New York, NY: Routledge.

Hattie, J., \& Timperley, H. (2007). The power of feedback. Review of Educational Research, 77, 81-112. doi: $10.3102 / 003465430298487$

Hofstede, G. (1986). Cultural differences in teaching and learning. International Journal of Intercultural Relations, 10, 301-320. doi:10.1016/0147-1767(86)90015-5

Jones, J. F. (1999). From silence to talk: Cross-cultural ideas on students' participation in academic group discussion. English for Specific Purposes, 18, 243-259. doi:10.1016/s0889-4906(97)00059-8

Joyce, K. M., \& Brown, A. (2009). Enhancing social presence in online learning: Mediation strategies applied to social networking tools. Online Journal of Distance Learning Administration, XII(IV). Retrieved from http://www.westga.edu/ distance/ojdla/

Kern, R., Ware, P., \& Warschauer, M. (2004). Crossing frontiers: New directions in online pedagogy and research. Annual Review of Applied Linguistics, 24, 243-260. doi:10.1017/S0267190504000091

Kluger, A. N., \& DeNisi, A. (1996). The effects of feedback interventions on performance: A historical review, a meta-analysis, and a preliminary feedback intervention theory. Psychological Bulletin, 119, 254-284. doi:10.1037/0033-2909.119.2.254

Krause, S. D. (2005). Blogs as a tool for teaching, The Chronicle of Higher Education, 51, 33-36 Retrieved from http://chronicle.com/section/Home/5

Krause, U.-M., Stark, R., \& Mandl, H. (2009). The effects of cooperative learning and feedback on elearning in statistics. Learning and Instruction, 19, 158-170. doi:10.1016/j.learninstruc.2008.03.003

Lee, I. (2008). Student reactions to teacher feedback in two Hong Kong secondary classrooms. Journal of Second Language Writing, 17, 144-164. doi:10.1016/j.jslw.2007.12.001

Levy, M. (2009). Technologies in use for second language learning. The Modern Language Journal, 93 , 769-782. doi:10.1111/j.1540-4781.2009.00972.x

Lincoln, Y. S., \& Guba, E.G. (1995). Naturalistic inquiry. Newbury Park, CA: Sage.

Liu, S.-Y., \& Shih, Y.-C. D. (2007). Using weblogs for college EFL writing: A case study. In H. C. Y. Leung, K. Cheung, \& W. Dai (Ed.), Selected Papers from the Sixteenth International Symposium on English Teaching (Vol. 2, pp. 212-222). Taipei: Crane (CD-ROM Publication).

Lloyd, C., \& Trangmar, R. (2012). Investigating the implications of Hattie's (2012) synthesis of metaanalyses for teaching higher education in further education. Teacher Education Network Journal, 4, 59-76. Retrieved from http://194.81.189.19/ojs/index.php/TEAN/index

Müller-Hartmann, A. (2007). Teacher role in telecollaboration: Setting up and managing exchanges. In R. O'Dowd (Ed.), Online intercultural exchange: An introduction for foreign language teachers (pp. 167-192). Tonawanda, NY: Multilingual Matters.

Mynard, J. (2007). A blog as a tool for reflection for English language learners. Asian EFL Journal, 24(2), 1-10. Retrieved from http://asian-efl-journal.com/ 
Nicol, D., \& Macfarlane-Dick, D. (2006). Formative assessment and self-regulated learning: A model and seven principles of good feedback practice. Studies in Higher Education, 31, 199-218. doi:10.1080/03075070600572090

O'Dowd, R., \& Waire, P. (2009). Critical issues in telecollaborative task design. Computer Assisted Language Learning, 22, 173-188. doi:10.1080/09588220902778369

Parr, J. M., \& Timperley, H. S. (2010). Feedback to writing, assessment for teaching and learning and student progress. Assessing Writing, 15, 68-85. doi:10.1016/j.asw.2010.05.004

Pegrum, M. (2009). From blogs to bombs: The future of digital technologies in education. Crawley: UWA Publishing.

Pinkman, K. (2005). Using blogs in the foreign language classroom: Encouraging learner independence. The JALT CALL Journal, 1, 12-24. Retrieved from http://journal.jaltcall.org/

Sadler, D. R. (2010). Beyond feedback: Developing student capability in complex appraisal. Assessment \& Evaluation in Higher Education, 35, 535-550. doi:10.1080/02602930903541015

Simpson, O. (2013). Supporting students in online, open \& distance learning. New York, NY: Taylor \& Francis.

Skehan, P. (1998). A cognitive approach to language learning. Oxford: Oxford University Press.

Sun, Y.-C. (2009). Voice blog: An exploratory study of language learning. Language Learning and Technology, 13, 88-103. Retrieved from http://1lt.msu.edu/

Tallent-Runnels, M. K., Thomas, J. A., Lan, W. Y., Cooper, S., Ahern, T. C., Shaw, S. M., et al. (2006). Teaching courses online: A review of the research. Review of Educational Research, 76, 93-125. doi:10.3102/00346543076001093

Ware, P., \& Canado, M. L. P. (2007). Grammar and feedback: Turning to language form in telecommunication. In R. O'Dowd (Ed.), Online intercultural exchange: An introduction for foreign language teachers (pp. 107-126). New York, NY: Multilingual Matters.

Williams, J. B., \& Jacobs, J. (2004). Exploring the use of blogs as learning spaces in the higher education sector. Australasian Journal of Educational Technology, 20(2), 232-247. Retrieved from http://www.ascilite.org.au/ajet/submission/index.php/AJET/index

Williams, B., Brown, T., \& Benson, R. (2013). Feedback in digital environment. In D. Boud \& E. Molloy (Eds.), Feedback in higher and professional education: Understanding it and doing it well (pp. 125139). New York, NY: Taylor \& Francis.

Willis, J. (2001). Foundational assumptions for information technology and teacher education. Contemporary Issues in Technology and Teacher Education, 1, 305-320. Retrieved from http://www.citejournal.org/vol1/iss1/frontpages/toc.html

$\mathrm{Wu}, \mathrm{W}$. S. (2006). The effect of blog peer review and teacher feedback on the revisions of EFL writers. Journal of Education and Foreign Languages and Literature, 5, 125-139. Retrieved from http://www.airiti.com/

Corresponding author: Wen-Chun Chen, ginawenchunchen@gmail.com

Australasian Journal of Educational Technology (C) 2014.

Please cite as: Chen, W-C. (2014). Actual and preferred teacher feedback on student blog writing. Australasian Journal of Educational Technology, 30(4), 402-414. 